IOSR Journal of Pharmacy

ISSN: 2250-3013, www.iosrphr.org

||| Volume 2 Issue 5 ||| Sep-Oct. 2012 ||| PP.12-23

\title{
Effects of Chronic Imipramine Combined With Swimming Exercise on Memory in Mice
}

\author{
Rozza $\mathrm{LM}^{1}$, Baldança $\mathrm{DCG}^{1}$, Lima $\mathrm{DD}^{2}$, Cruz $\mathrm{JN}^{3}$, Dal Magro DD ${ }^{4}$, \\ Cruz JGP*4 \\ ${ }^{I}$ Department of Veterinary Medicine, Universidade Regional de Blumenau, Santa Catarina, Brazil. \\ ${ }^{2}$ Department of Pharmacy, Universidade da Região de Joinville, Santa Catarina, Brazil. \\ ${ }^{3}$ Department of Medicine, Universidade do Extremo Sul Catarinense, Santa Catarina, Brazil. \\ ${ }^{4}$ Department of Natural Sciences, Universidade Regional de Blumenau, Santa Catarina, Brazil.
}

\begin{abstract}
The aim of this study was to investigate in mice the possible effects of imipramine treatment and/or swimming exercise in the animal's models of anxiety and memory. The results suggest that imipramine treatment and/or swimming exercise induces an anxiolytic-like effect in mice in the elevated plus-maze and open-field tests. In addition, comparison within each group during the five days of Morris water maze test, showed a decrease of latency time us groups imipramine from the second day the testing, with increased in exploration ratio in both short and long-term object recognition memory. However, the mice previously exposed to swimming exercise did not differ from saline controls in the memory tests. The results provide evidence that swimming exercise prevents the increased in learning and memory improvement induced by imipramine treatment, while not influencing their anxiotytic effects; a fact that should be relevant to a better understanding of the combination of behavioral and pharmacological therapy.
\end{abstract}

Keywords-Imipramine, Morris water maze, Object recognition, swimming exercise

\section{INTRODUCTION}

Imipramine or physical exercise has been used as an important in the treatment of depressive disorders $[1,2]$. It is interesting to note that a combination of behavioral and pharmacological therapy is considered the most effective clinical intervention for depression [3]. Previous studies have indicated that chronic exercise has some similar central nervous system effects as observed after imipramine treatment. One of the most reproducible effects of exercise or imipramine treatment seems to be an enhanced hippocampal neurogenesis [4, 5]. Adult hippocampal neurogenesis is a unique form of neural circuit plasticity that results in the generation of new neurons throughout life [6]. The levels of adult hippocampal neurogenesis are increased by interventions that are associated with beneficial effects on cognition and mood [7].

The time-course for brain-derived neurotrophic factor (BDNF) mRNA up-regulation by antidepressant treatment is chronic (two weeks), and appears to approximate the time required for clinical response to antidepressant treatment in humans [8]. The regulation of BDNF mRNA by general physical activity has been demonstrated to be very rapid [9]. The combined treatment of physical exercise and imipramine potentiated the expression of BDNF mRNA levels in the hippocampal formation above the level observed with either exercise or drug treatment alone [10]. The demonstration of an exon-specific, apparently co-operative regulation of BDNF transcription by these two interventions supports the possibility that antidepressant treatment and physical exercise may act through convergent molecular mechanisms [11]. However, Van Hoomissen et al. (2003) reported that the combined treatment of physical exercise and imipramine do not influence BDNF mRNA levels [12]. A factor, which may have contributed to such inconsistencies, is the fact that the delay between the last administration of imipramine and neurochemical analysis varies greatly amongst studies. The isolation of brain tissue occurred 24 or $48 \mathrm{~h}$ after imipramine injection, respectively. The monoamine theory of depression does not completely explain the neurobiology of depression and it is now believed that depression is a heterogeneous disease in which multiple neurochemical systems are interacting. The finding that the expression of BDNF mRNA levels can be increased by chronic antidepressant treatment [8] has led to a hypothesis that BDNF expression might also be regulated by a calcium- or cyclic adenosine monophosphate (cAMP)-dependent pathway, following the activation of monoaminergic neurotransmitter receptors [13].

It has been generally accepted that exercise and/or imipramine treatment produces benefits for depressed patients. Introducing physical exercise in therapeutic regimes would be an innovative approach that 
could significantly reduce the severity of psychopathological and cognitive symptoms in patients $[14,15,16]$. However, only in recent years has there been an increasing interest in the scientific investigation of its effects on the brain and cognition. Human research shows that exercise or imipramine helps in the prevention and treatment of depression [15, 17] and improves cognitive functions $[18,19]$. However, in spite of this generally positive impression, physical exercise and imipramine has not been broadly implemented in mental health intervention. In part, this is probably due to the fact that, together with positive results, there are also many studies showing no effect of exercise or imipramine [20,21], and even a few describing negative effects [21, 22]. The methodological diversity of these studies makes it difficult to establish which other variables (from genetic differences to features of the task used in the study) interact with exercise to produce this wide range of results. Animal research could help not only to broaden knowledge of the behavior mechanisms involved in these effects but also to clarify the modulatory effect of these other variables in a more controlled environment. With respect to animal studies on learning and memory, physical exercise or imipramine has been shown to have a beneficial effect on water maze [23, 24], object recognition [25, 26], passive avoidance [27, 28], polejumping active avoidance $[29,30]$ and radial arm maze $[31,32]$. However, there are also a few studies using similar tasks that have reported no effects or even a negative effect $[33,34]$. We can note that most of these learning tasks depend in some manner on the integrity of hippocampus. It has been demonstrated that general physical activity [35] and antidepressant treatment [25] each lead to increased neurogenesis in the mice hippocampus. In addition, these interventions, when combined, may increase neurogenesis in a convergent manner $[10,11]$. However, the behavior evaluation on antidepressant treatments combined with swimming exercise in mice has not been studied. In this context, the present experiments were designed to investigate possible effects of imipramine treatment and/or swimming exercise in the animal's models of anxiety and memory.

\section{MATERIAL AND METHODS}

Animals:

Male Swiss mice, genetically heterogeneous, aging 45 days and weighing 25-30 g, were obtained from the animal house of the Regional University of Blumenau. After arrival in the sectorial animal house of the laboratory, these animals were housed in groups of ten per opaque plastic cage $(50 \times 30 \times 15 \mathrm{~cm})$, with wood shaving bedding and wire mesh tops, under a standard light cycle (12-h light/dark phase; lights on at 07:00 h), in a temperature-controlled environment $\left(23 \pm 1^{\circ} \mathrm{C}\right)$, and the relative humidity was $55 \pm 10 \%$. During the light and dark phases, the rats were exposed to a light intensity of approximately 500 and 0.025 lux, respectively. These lux values were chosen because they were the closest values (in our laboratory) possible to natural daytime and nighttime light. During the whole experimental period, the animals received commercial chow for rodents (Nuvital, PR, Brazil) and filtered tap water ad libitum. The room was entered at irregular intervals an average of once every 2 or 3 days for the purposes of cleaning cages, placing food and water, and so on. Animals were acclimatized to the animal housing facilities for at least 1 week before starting the experiments. The experiments reported in this article were performed in compliance with the recommendations of Brazilian Society of Neuroscience and Behavior (SBNeC), which are based on the US National Institutes of Health Guide for Care and Use of Laboratory Animals.

\section{Chronic imipramine treatment.}

The mice were randomly assigned to one of two experimental groups: sedentary and swimming exercise. Animals received daily an intraperitoneal injection of imipramine (10, 20 or $30 \mathrm{mg} / \mathrm{kg} / \mathrm{day}$; Sigma) for treatment period of 14 days before the behavioral tests. Control animals received saline (vehicle) injections. At the end of the treatment period and twenty-four hours after the last exercise bout, all rats were submitted individually to behavioral tests.

Adaptation to the water.

All the mice were adapted to the water before the beginning of the experiment. The adaptation consisted of keeping the animals in shallow water at $32 \pm 1^{\circ} \mathrm{C}, 5$ days during one week in sessions lasted $10 \mathrm{~min}$, from 08:00 to 17:30 $\mathrm{h}$. The purpose of the adaptation was reducing the stress without, however, promoting physical training adaptations.

\section{Exercise training.}

The mice of the exercise group were trained to swim $30 \mathrm{~min} /$ day, 5 days a week, during 8 weeks in a progressively increasing moderate swimming program with no weight loading in free style. This has been validated by previous reports [36]. Daily swimming exercise was performed in a large water tank $(100 \mathrm{~cm} \times 40$ $\mathrm{cm} \times 90 \mathrm{~cm}$ ) at $32 \pm 1{ }^{\circ} \mathrm{C}$ a depth of $60 \mathrm{~cm}$. Exercise sessions lasted $10 \mathrm{~min}$ on the first day of the training period and was increased by 10 min each 7 days. At the end of the 7th day the animals swam continuously for 20 min. Continuous exercise $(30 \mathrm{~min})$ was performed from the 14th day until the end of the training period. Sedentary mice placed in shallow water at $32 \pm 1^{\circ} \mathrm{C}, 30 \mathrm{~min}, 5$ days/week, were used as controls. At the end of the training period and twenty-four hours after the last exercise bout, all mice were submitted individually to behavioral 
tests. Those experiments were carried out in a sound-attenuated and temperature-controlled $\left(23 \pm 1^{\circ} \mathrm{C}\right)$ room, illuminated with one $40-\mathrm{W}$ fluorescent light placed $1.3 \mathrm{~m}$ away from the apparatus. All behavioral procedures were conducted during the light phase (between 8:00 and 12:00 h), when rodents are less active. To minimize possible circadian influences on mice, experimental and control observations were alternated. The observer stayed in the same room, $1 \mathrm{~m}$ or so away from the apparatus.

\section{Elevated plus-maze test.}

\section{BEHAVIORAL TESTS}

The elevated plus-maze test involves conflict between the desire to explore and the desire to avoid the anxiogenic stimuli of open and high spaces [37]. The test is considered to be a measure of generalized anxiety since agents used to alleviate generalized anxiety disorder symptoms modify defensive behaviors evoked by the model [38]. The equipment consisted of a "plus" wooden shaped maze with two opposite open arms (30 x 7,5 $\mathrm{cm})$ and two enclosed arms $(30 \times 7,5 \times 21,5 \mathrm{~cm})$ extended from a central platform $(7,5 \times 7,5 \mathrm{~cm})$. The floor of the maze was painted with impermeable epoxy resin, to avoid urine impregnation. The maze was elevated to a height of $30 \mathrm{~cm}$ above the floor. A $0,3 \mathrm{~cm}$ high edge of plexiglas circumscribed the open arms to avoid incidental falls. Each individual animal was tested for 5 min starting from the platform facing the closed arm. The time spent in the open arms and enclosed arms as well as the entries into these compartments were measured. An open-arm entry was defined as all four of the paws being placed in the open arm. We also included ethologically derived measures related to the defensive pattern of risk assessment behavior, which has been proven very sensitive to changes in anxiety [39]. Risk assessment is measures comprised for time spent in the head-dipping (exploratory movement of head/shoulders over the side of the maze), and stretched attend postures (exploratory posture in which the body is stretched forward then retracted to the original position without any forward locomotion). Thus, the closed arms and center platform were designated as "protected" areas (i.e., offering relative security) and the "time protected" for head-dipping and stretched attend postures calculated as the time of these behaviors displayed in or from the protected area [40].

\section{Open-field test.}

The open-field test relies on a rodent's innate exploratory behavior counteracted by its natural aversion to open space [41]. The apparatus consisted of circular wooden box $(60 \mathrm{~cm}$ in diameter and $50 \mathrm{~cm}$ high) with an open top. In order to record locomotor activity, the open-field was subdivided into 17 parts. Animals were placed into the center of the open-field and allowed to explore freely for $5 \mathrm{~min}$. The following parameters were recorded: time the movement of the animal between parts spent in the central or peripheral zones of the apparatus are scored (ambulation); time for which the animal did not move at all (freezing); time rearing (rising on the hind paws) and time the animal performed self-cleaning (grooming). The total time spent ambulation and freezing was determined as a measure of activity. Exploration behavior in the open-field has also been used as a measure of defensive behavior, where increased line rearing responses are suggestive of a decrease in defensive behaviors.

\section{Morris water maze test.}

The Morris water maze was a circular pool $\left(60 \mathrm{~cm}\right.$ diameter and $30 \mathrm{~cm}$ height) filled with water $\left(32^{\circ} \mathrm{C}\right)$ to a depth of $14 \mathrm{~cm}$. The pool was located in a dimly lit, soundproof test room with a various visual cues, including a white-black colored poster on the wall, a halogen lamp and the experimenter. The maze was divided into four quadrants, and three equally spaced points served as starting positions around the edge of the pool. The order of the release positions varied systematically throughout the experiment. A circular escape platform $(6 \mathrm{~cm}$ diameter and $12 \mathrm{~cm}$ high) was located in one quadrant $1 \mathrm{~cm}$ below the water surface during the test. One familiarization and five acquisition sessions were performed using the Morris water maze. During the familiarization session and acquisition phase of the experiment, each mouse was given three trials. The delay between the trials was $60 \mathrm{~s}$, and a 1 day interval was used between each session. For each trial, the mouse was taken from the home cage and placed into the water maze at one of three randomly determined locations with its head facing the center of the water maze. After the mouse had found and climbed on to the platform, the trial was stopped, and the escape latency was recorded. If the mouse did not climb onto the platform in $60 \mathrm{~s}$, the trial was stopped, and the experimenter guided the mouse to the platform. The time escape latency was used as measures for the development of spatial memory.

\section{Object recognition test.}

The object recognition test measures non-spatial working memory in the mice and takes advantage of the mice unprompted nature to explore its surroundings [42]. This model is advantageous as it does not require punishment or reward and is quick and simple to implement. Mice are first exposed to two identical objects and then, following a specific delay, the mice are presented with one of the familiar objects and also a novel object. When the subject remembers the previous exposure to the familiar object, the mice will explore the novel object to a greater degree than that of the familiar one. All animals were habituated to the experimental arena in the absence of any specific behavioral stimulus for $20 \mathrm{~min} /$ day during 4 days. The objects, made of metal or glass, 
were fixed to the arena's floor with adhesive ribbon. In the pre-test two identical objects ( $\mathrm{M}$ and $\mathrm{N}$ ) were placed in the corners of the box. The test was repeated 2 hours later to test short-term memory (STM) or 24 hours later to evaluate long-term memory (LTM) after the pre-test. In the tests, one of the objects was changed for a new object (P, for STM or R, for LTM). The time allowed for exploration in each trial was 5 min. The positions of the objects (familiar or novel) were randomly permuted for each experimental animal and the arena was cleaned between trials. Exploration was defined as sniffing or touching the object with the nose and/or forepaws. Sitting on or turning around the object was not considered exploratory behavior. The time spent to explore each object was recorded by an observer blind to the treatment and expressed as total exploration time computed in seconds. Statistical analysis.

All data presented are expressed as the means \pm S.E.M., and each value reflects the mean of 10 animals per group. The means were compared by analysis of variance (ANOVA), followed by Newman-Keuls multiple comparisons test. A probability level of 0,05 were used to test for statistical significance.

\section{RESULTS}

Analysis of variance revealed significant differences between groups on the time spent by mice in the open arms of the plus-maze $(\mathrm{F}=5.833$; $\mathrm{p}<0,001$; Figure $1 \mathrm{~A})$. The experimental group imipramine sedentary $(\mathrm{S} 10-\mathrm{S} 30 \mathrm{mg} / \mathrm{kg}$ ) and swimming exercise (E0-E30 $\mathrm{mg} / \mathrm{kg}$ ), increased the time spent in the open arms on the day of experiment when compared to control sedentary (S0). In case of the enclosed arm time, there were significant differences between groups $(F=10.073 ; p<0,001$; Figure 1B). The experimental group imipramine sedentary $(\mathrm{S} 10=\mathrm{S} 30 \mathrm{mg} / \mathrm{kg}$ ) and swimming exercise $(\mathrm{E} 0-\mathrm{E} 30 \mathrm{mg} / \mathrm{kg})$, decreased the enclosed arm time when compared to control sedentary ( $\mathrm{S} 0)$. Analysis of variance revealed significant differences between groups on the number open arm entries $(\mathrm{F}=3.398 ; \mathrm{p}<0,01$; Figure $1 \mathrm{C})$. The experimental group imipramine sedentary (S10-S30 $\mathrm{mg} / \mathrm{kg}$ ) and swimming exercise (E0-E30 $\mathrm{mg} / \mathrm{kg}$ ), increased the time spent in the number open arm entries when compared to control sedentary (S0). There was no significant difference in groups in the number enclosed arm entries $(F=0.3174 ; p=0,9408$, Figure 1D) and risk assessment time $(F=1.870 ; p=0,1066$, Figure 1E).
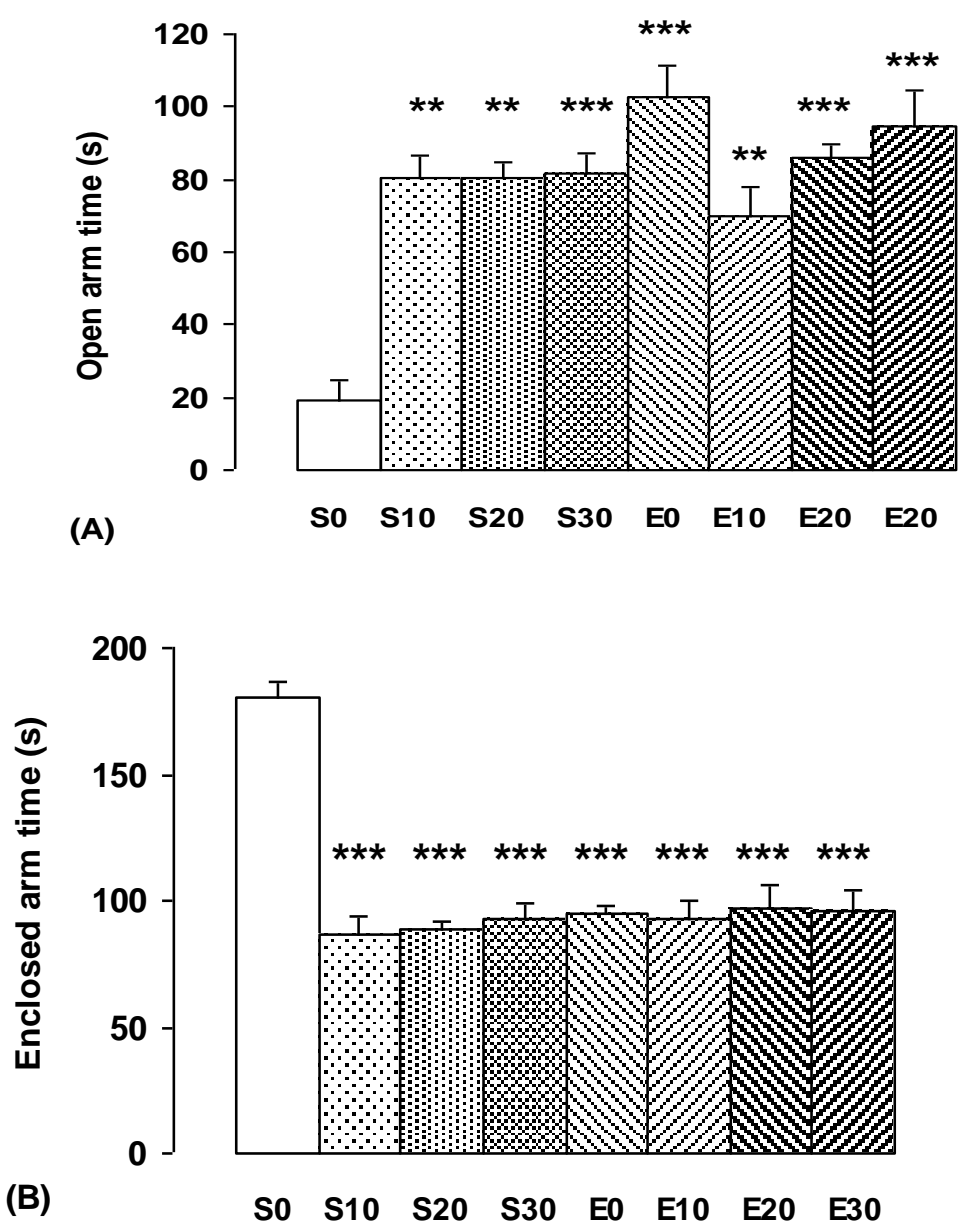

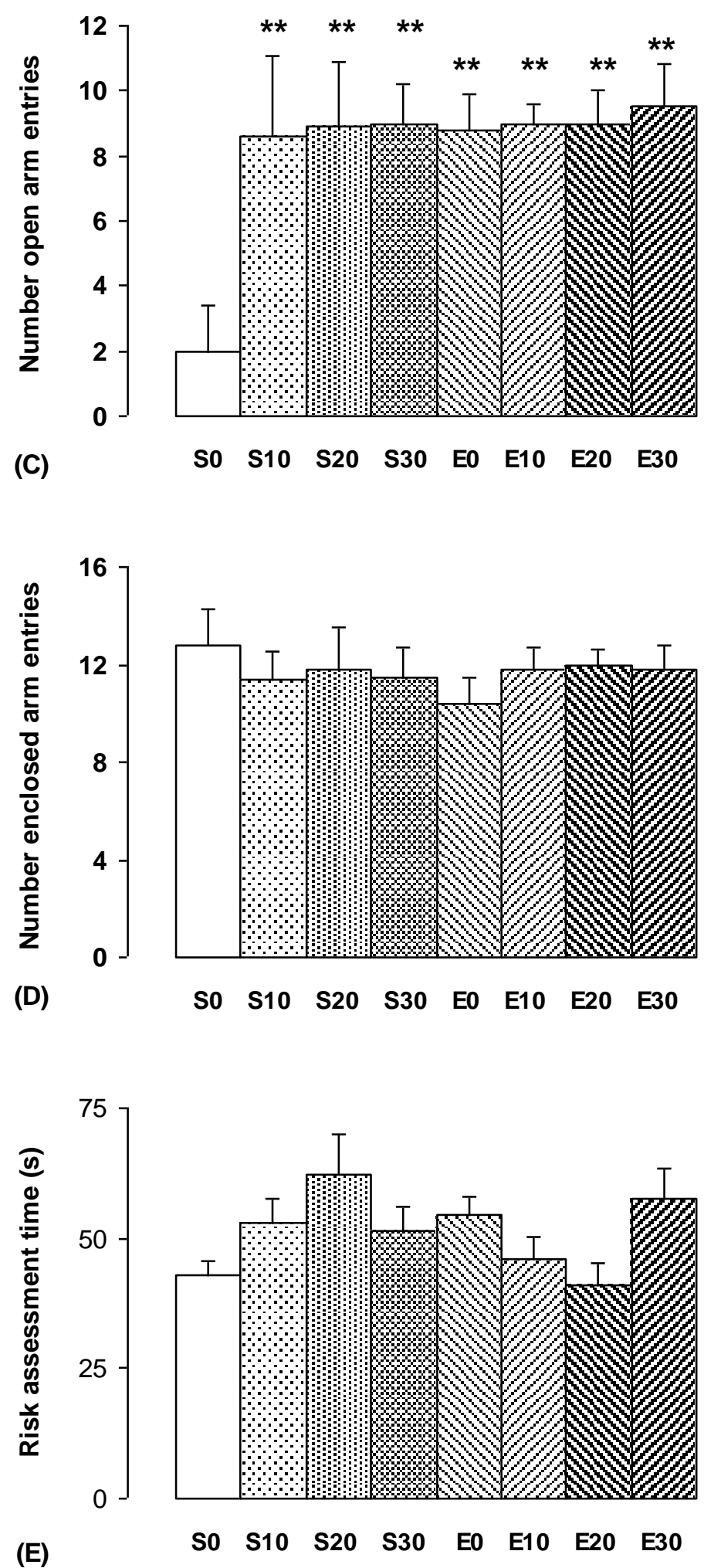

Figure 1. Behavioral responses on the elevated plus-maze of sedentary (S) and swimming exercise mice (E), 14 days after treated with imipramine $(0,10,20$ and $30 \mathrm{mg} / \mathrm{kg} / \mathrm{day})$ : (A) open arm time, (B) enclosed arm time, (C) number open arm entries, (D) number enclosed arm entries, and (e) risk assessment time. Bars represent the means for each group and the vertical lines represent the standard errors of the means. NewmanKeuls test showed that groups with asterisks are significantly different versus $\mathrm{S} 0(\mathrm{n}=10 ; * * \mathrm{p}<0,01$ and $* * * \mathrm{p}<0,001)$. 
Analysis of variance revealed significant differences between groups on the time spent by mice in the ambulation/interior zone time of the open-field $(F=5.647 ; p<0,001$; Figure 2A). The experimental group imipramine sedentary (S30 mg/kg) and swimming exercise (E0-E30 mg/kg), increased the time spent in the ambulation/interior zone time when compared to control sedentary (S0). There was no significant difference in groups in the ambulation/outside zone time $(\mathrm{F}=2.113 ; \mathrm{p}=0,0656$; Figure $2 \mathrm{~B})$, freezing $(\mathrm{F}=0.9724 ; \mathrm{p}=$ 0,4651 , Figure 2C), and rearing $(\mathrm{F}=0.9089 ; \mathrm{p}=0,5100$; Figure 2D). Analysis of variance revealed significant differences between groups on the grooming $(F=16.324 ; p<0,001 ;$ Figure $2 \mathrm{E})$. The experimental group imipramine sedentary $(\mathrm{S} 10-\mathrm{S} 30 \mathrm{mg} / \mathrm{kg})$ and swimming exercise $(\mathrm{E} 0-\mathrm{E} 30 \mathrm{mg} / \mathrm{kg})$, increased the time spent in the grooming when compared to control sedentary (S0).
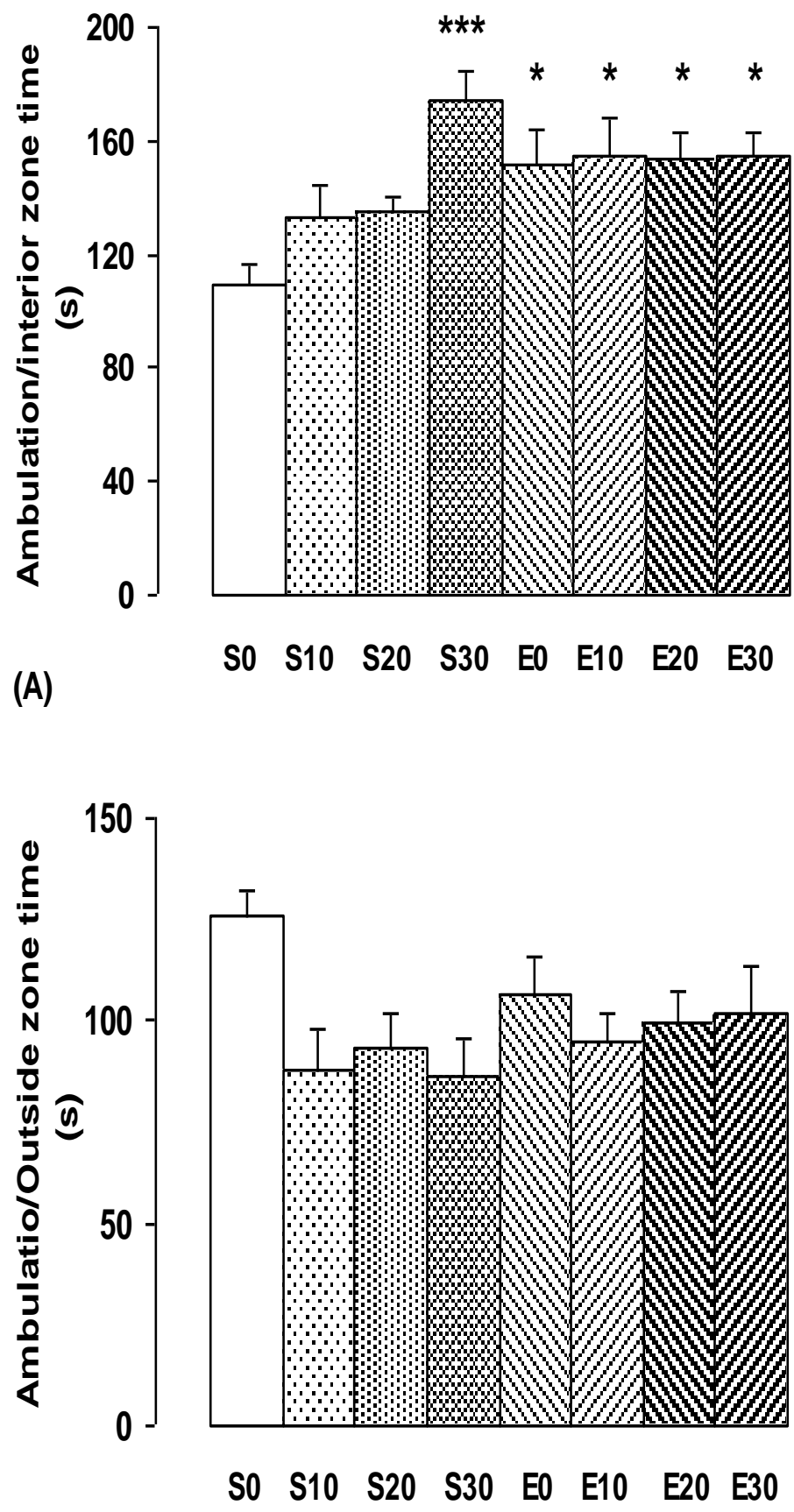

(B) 

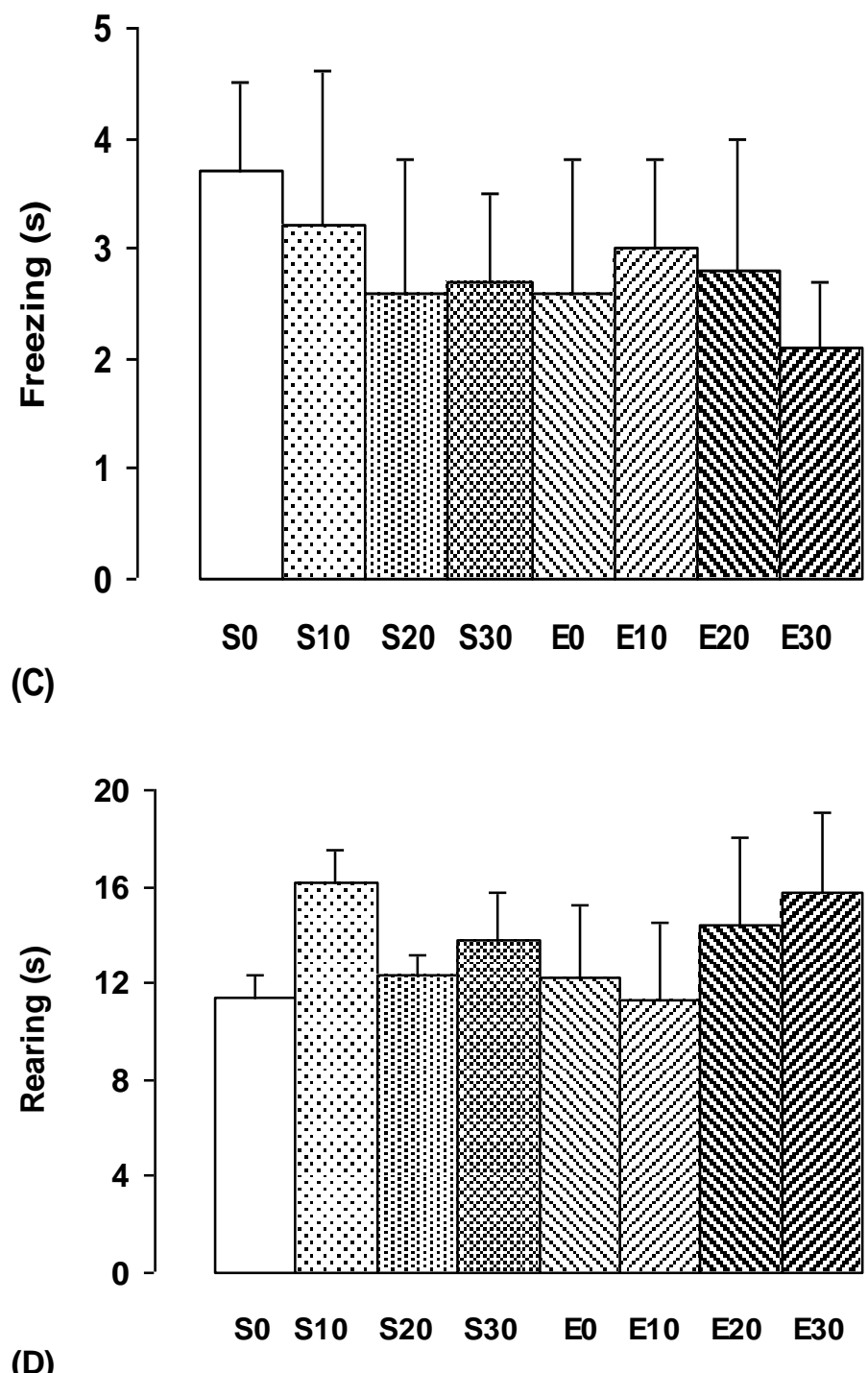

(D)

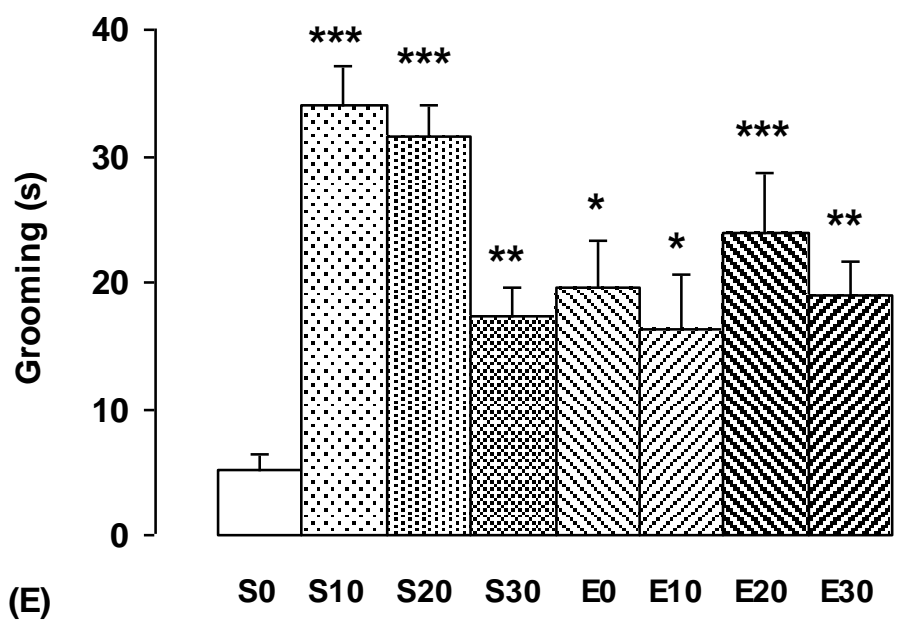

Figure 2. Behavioral responses on the open-field of sedentary (S) and swimming exercise mice (E), 14 days after treated with imipramine $(0,10,20$ and $30 \mathrm{mg} / \mathrm{kg}$ ): (A) ambulation/interior zone time, (B) ambulation/outside zone time, (C) freezing, (D) rearing, and (E) grooming. Bars represent the means for each 
group and the vertical lines represent the standard errors of the means. Newman-Keuls test showed that groups with asterisks are significantly different versus $\mathrm{S} 0(\mathrm{n}=10 ; * \mathrm{p}<0,05 ; * * \mathrm{p}<0,01 ; * * * \mathrm{p}<0,001)$.

Analysis of variance revealed significant enhancement in spatial learning as decreased of escape latency to the platform in the Morris water maze, during the five days of testing, Mice of group imipramine sedentary $(\mathrm{S} 20 \mathrm{mg} / \mathrm{kg} ; \mathrm{F}=10.718 ; \mathrm{p}<0,001$ and $\mathrm{S} 30 \mathrm{mg} / \mathrm{kg} ; \mathrm{F}=9.996 ; \mathrm{p}<0,001$; Figure 3A), decreased on second day the testing; while in groups swimming exercise $(\mathrm{E} 0 \mathrm{mg} / \mathrm{kg} ; \mathrm{F}=2.946 ; \mathrm{p}<0,05-\mathrm{E} 10 \mathrm{mg} / \mathrm{kg} ; \mathrm{F}=$ $3.422 ; \mathrm{p}<0,05$ - E20 mg/kg; F = 4.971; $<<0,05-\mathrm{E} 30 \mathrm{mg} / \mathrm{kg} ; \mathrm{F}=3.400 ; \mathrm{p}<0,05 ;$ Figure 3B), after five days.

so

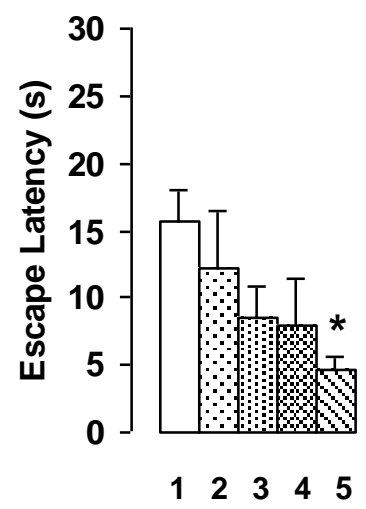

(A)
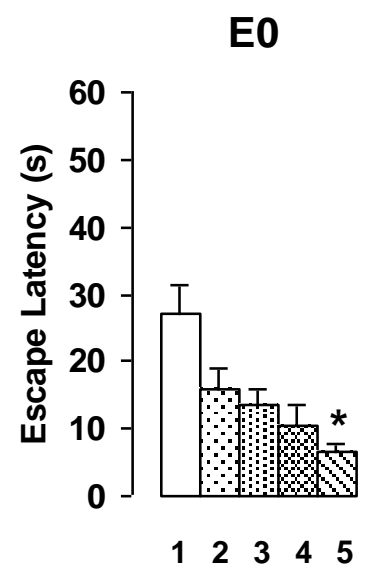

(B)
S10

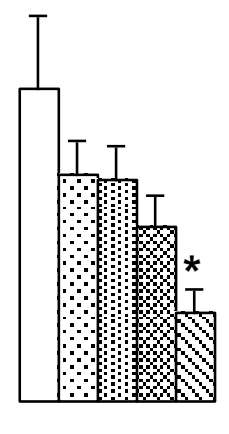

$\begin{array}{lllll}1 & 2 & 3 & 4 & 5\end{array}$
S20

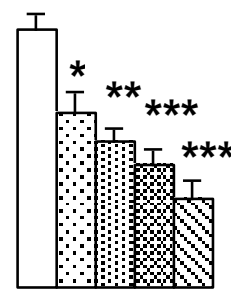

$\begin{array}{lllll}1 & 2 & 3 & 4 & 5\end{array}$
S30

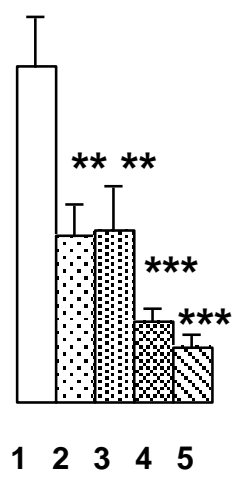

Day

E10

E20

E30

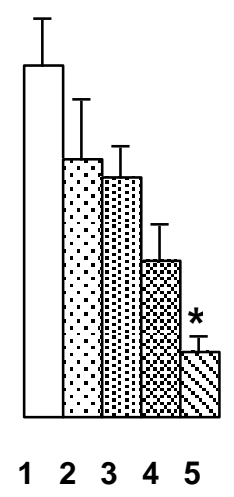

Day

Figure 3. Behavioral responses of sedentary (S) and swimming exercise mice (E), 14 days after treated with imipramine $(0,10,20$ and $30 \mathrm{mg} / \mathrm{kg}$ ), before trained during 5 days in Morris water maze: (A) escape latency of sedentary, and (B) escape latency of swimming exercise. Bars represent the means for each group and the vertical lines represent the standard errors of the means. Newman-Keuls test showed that groups with asterisks are significantly different versus 1 day $(n=10 ; * \mathrm{p}<0,05 ; * * \mathrm{p}<0,01 ; * * * \mathrm{p}<0,001)$.

Analysis of variance revealed significant enhancement in non-spatial learning in object recognition test. Mice of group imipramine sedentary $(\mathrm{S} 10 \mathrm{mg} / \mathrm{kg} ; \mathrm{F}=10.700 ; \mathrm{p}<0,001-\mathrm{S} 20 \mathrm{mg} / \mathrm{kg} ; \mathrm{F}=32.202 ; \mathrm{p}<0,001-\mathrm{S} 30$ $\mathrm{mg} / \mathrm{kg} ; \mathrm{F}=4.138 ; \mathrm{p}<0,01$; Figure 4A), improved both short- (STM) and long-term object recognition memory (LTM). However, imipramine treatment combined with swimming exercise did not affect short- or long-term memory retention $(p>0,05$; Figure $4 B)$. 
So

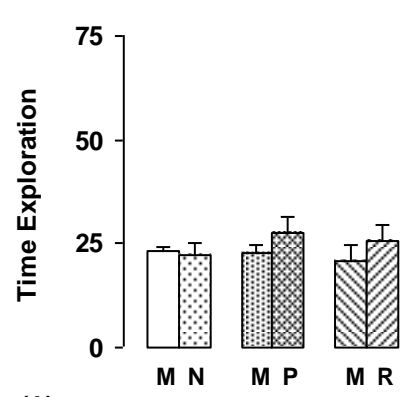

(A)
S10

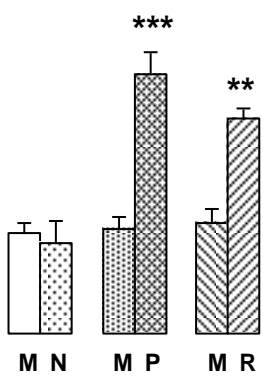

E10

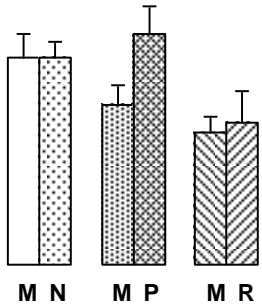

S20

S30

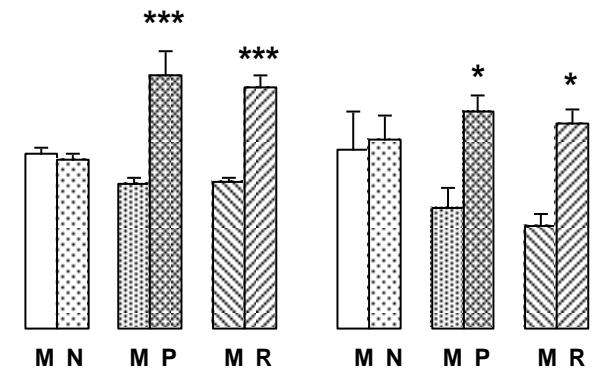

E20

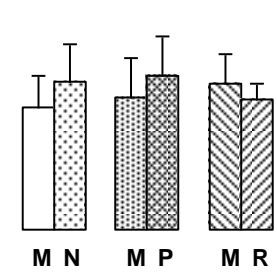

(B)

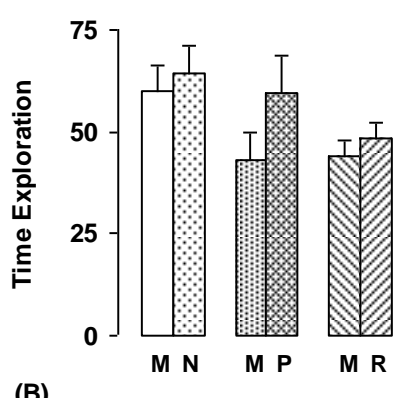

Figure 4. Behavioral responses on object recognition memory of sedentary (S) and swimming exercise mice (E), 14 days after treated with imipramine $(0,10,20$ and $30 \mathrm{mg} / \mathrm{kg}$ ): (a) time exploration of sedentary, and (B) time exploration of swimming exercise. Mice were exposed to two identical objects ( $\mathrm{M}$ and $\mathrm{N}$ ) in the pretest session. Two hours later a short-tem memory (STM) test was carried out: animals were exposed to a familiar object (M) and a novel object (P). The long-term memory (LTM) was measured $24 \mathrm{~h}$ after pre-test: the animals were exposed again to the familiar object (M) and to another novel object (R). Bars represent the means for each group and the vertical lines represent the standard errors of the means. Newman-Keuls test showed that groups with asterisks are significantly different $(\mathrm{n}=10 ; * \mathrm{p}<0,05 ; * * \mathrm{p}<0,01 ; * * * \mathrm{p}<0,001)$.

\section{DISCUSSION}

The results suggest that imipramine treatment, swimming exercise and imipramine treatment combined with swimming exercise induced an anxiolytic-like effect in mice in the elevated plus-maze test. These symptoms were observed in S10-S30 and E0-E30, through increased in time spent and entries in the open arms (Figure 1A and 1C); while occurs decrease in the time spent in the enclosed arm (Figure 1B). The behaviors that are typically recorded when rodents are in the elevated plus-maze are the time spent and entries made on the open and closed arms. Behavior in this task (i.e., activity in the open arms) reflects a conflict between the rodent's preference for protected areas (e.g., closed arms) and their innate motivation to explore novel environments [37]. Thus anxious animals will spend most time in the closed arms while less anxious animals will explore open areas longer [38]. These results strongly indicate that imipramine treatment and/or swimming exercise results in an improved coping with aversive situations, thus, leading to a reduced anxiety level.

The differences in anxiotypic behavior expressed by these animals are not limited to their performance on the elevated plus-maze. The novel environment is an established measure of general anxiotypic behavior, and levels of locomotion, rearing and grooming in this paradigm can be used as indices of an anxiety-like state in mice [41]. The open-field is another test that takes advantage of the rodent's tendency to explore new environments, as measured by ambulation [43]. Typically, the rodents are more active and remain longer in the periphery of the apparatus in comparison to the central areas, a preference that has been interpreted as being determined by thigmotaxis [41]. The S30 and E0-E30 increased the time spent in the ambulation/interior zone (Figure 2A), indicated by a reduction of anxiety. Locomotion can be assessed by time spent in each of two zones (central and peripheral) can be used in addition to the classical test as indicators of anxiety [44]. Traveling close to the wall is an important feature of the mice, and it has been suggested that the wall confers security while the center is anxiogenic [37]. However, exploratory behaviors also drive the mouse to explore all the open space. 
Spatial distribution of mouse position is then expected to be non homogeneous. The increased the time spent in the ambulation/interior zone indicated a reduction of fear/anxiety. In addition, S10-S30 and E0-E30 increased the time spent in the grooming in open-field (Figure 2E).

Several physiological mechanisms have been suggested to explain the beneficial effects of imipramine and physical exercise on anxiety $[40,45]$. Although, it has been shown that imipramine and physical exercise can regulate signal transduction pathways in several regions of the brain and alter the function of several neurotransmitter systems [46], recent neurochemical and behavioral data concerning a neuroprotective role for imipramine and physical exercise [47], its primary effects on anxiety and memory in general are debatable. Animal studies also suggest that imipramine may improve memory deficits induced by environmental stressors or neuropathological insult, but whether imipramine is effective in altering learning combined with physical exercise is unknown. Comparison within each group during the five days of Morris water maze test, the latency time revealed a significant progressive decrease in groups S20 and S30 from the second day the testing (Figure $3 \mathrm{~A}$ and $3 \mathrm{~B}$ ). Furthermore, we may conclude from these behavioral data that the effects of imipramine may be specific to particular cognitive processes, especially those involving the hippocampus, as has been previously suggested [24, 48]. In support of our findings of imipramine enhancements in learning in animals, a clinical report indicated that imipramine may be effective in diminishing learning deficits [19].

Since we were interested in determining the effects of imipramine treatment and/or swimming exercise on spatial learning, testing this aspect of exploratory behavior allowed furthering characterizing the possible effects of imipramine and/or swimming exercise in eliciting a response to novelty. Object recognition memory, is agreed to be dependent on the perirhinal cortex. Whether it is a hippocampal or non-hippocampal dependent task is still in debate. While some studies reported that the task does not require the hippocampus, several studies support the fact that the hippocampus contributes to learned object familiarity [49]. Mice of group S10S30 increased in exploration ratio in both short (STM) and long-term object recognition memory (LTM), when compared to S0. The groups exercise did not differ significantly from S0 (Figure 4). Object recognition memory is assessed by the preference that normal animals display for exploring novel, rather than familiar, complex objects [42]. This data agrees with previous findings showing that imipramine treatment increases the approaches to novel objects [25]. It should be noted, however, that there was no significant difference in object recognition the group receiving imipramine treatment combined with swimming exercise prior to the test.

Consequently, we may conclude from these behavioral data that the effects of imipramine may be specific to particular cognitive processes, especially those involving the hippocampus and perirhinal cortex, as has been previously suggested [24, 25, 48]. The observed differences cannot be attributed to changes in anxiety, since no differences between groups in the specific anxiety tests carried out in plus-maze and open-field (Figure 1 and 2). Thus, it is likely that the differences observed in performance during the two retention sessions are attributable to a modulation of learning and memory processes. Interestingly, we demonstrated that improve memory formation occurs with imipramine treatment than with the combination of swimming exercise and imipramine treatment. This suggests that swimming exercise blocks the behavioral improvement induced by imipramine treatment. Despite a substantial number of studies demonstrating that adult-born neurons are necessary for mediating specific cognitive functions, as well as some of the behavioral effects of antidepressants, it is unknown whether an increase in adult hippocampal neurogenesis occurs on imipramine treatment combined with swimming exercise It is interesting to note that a combination of behavioral and pharmacological therapy is considered the most effective clinical intervention for depression.

\section{CONCLUSION}

A great deal of scientific evidence supports exercise and imipramine treatment as being beneficial to mental health. These benefits include a reduction in anxiety, depression and negative mood. The present study found that swimming exercise and/or imipramine treatment induced an anxiolytic-like effect, indicating that interactions between physical activity and/or imipramine may be beneficial. However, the swimming exercise blocks the learning and memory improvement induced by imipramine treatment in mice. Our results provide evidence that stimulates investigation of the possibility that swimming exercise, in conjunction with imipramine treatment, could represent a new approach to improvement of behavioral management in depression.

\section{CONFLICT OF INTEREST STATEMENT}

We declare that we have no conflict of interest. 


\section{REFERENCES}

[1]. B. Haenisch, H. Bönisch. Depression and antidepressants: insights from knockout of dopamine, serotonin or noradrenaline re-uptake transporters. Pharmacol. Ther., 129(3), 2011, 352-68.

[2]. J. Mota-Pereira, J. Silverio, S. Carvalho, J.C. Ribeiro, D. Fonte, J. Ramos. Moderate exercise improves depression parameters in treatment-resistant patients with major depressive disorder. J. Psych. Res., 45(8), 2011, 1005-11.

[3]. M. Rizzo, F. Creed, D. Goldberg, N. Meader, S. Pilling. A systematic review of non-pharmacological treatments for depression in people with chronic physical health problems. J. Psychosom. Res., 71(1), 2011, 18-27.

[4]. A.P. Schiavon, H. Milani, C.V. Romanini, M.L. Foresti, O.W. Castro, N. Garcia-Cairasco, R.M. de Oliveira. Imipramine enhances cell proliferation and decreases neurodegeneration in the hippocampus after transient global cerebral ischemia in rats. Neurosci. Lett., 470(1), 2010, 43-8.

[5]. S.A. Wolf, A. Melnik, G. Kempermann. Physical exercise increases adult neurogenesis and telomerase activity, and improves behavioral deficits in a mouse model of schizophrenia. Brain Behav. Immun., 25(5), 2011, 971-80.

[6]. A. Sahay, K.N. Scobie, A.S. Hill, C.M. O'Carroll, M.A. Kheirbek, N.S. Burghardt, A.A. Fenton, A. Dranovsky, R. Hen. Increasing adult hippocampal neurogenesis is sufficient to improve pattern separation. Nature, 472(7344), 2011, 466-70.

[7]. D.T. Balu, I. Lucki. Adult hippocampal neurogenesis: regulation, functional implications, and contribution to disease pathology. Neurosci. Biobehav. Rev., 33(3), 2009, 232-52.

[8]. M. Nibuya, S. Morinobu, R.S. Duman. Regulation of BDNF and trkB mRNA in rat brain by chronic electroconvulsive seizure and antidepressant drug treatments. J. Neurosci., 15(11), 1995, 7539-47.

[9]. H.S. Oliff, N.C. Berchtold, P. Isackson, C.W. Cotman. Exercise-induced regulation of brain-derived neurotrophic factor (BDNF) transcripts in the rat hippocampus. Molec. Brain Res., 6(1-2), 1998, 147-53.

[10]. A. Russo-Neustadt, R.C. Beard, C.W. Cotman. Exercise, antidepressant medications, and enhanced brain derived neurotrophic factor expression. Neuropsychopharmacol., 21(5), 1999, 679-82.

[11]. A.A. Russo-Neustadt, R.C. Beard, Y.M. Huang, C.W. Cotman. Physical activity and antidepressant treatment potentiate the expression of specific brain-derived neurotrophic factor transcripts in the rat hippocampus. Neuroscience, 101(2), 2000, 305-12.

[12]. J.D. Van Hoomissen, H.O. Chambliss, P.V. Holmes, R.K. Dishman. Effects of chronic exercise and imipramine on mRNA for BDNF after olfactory bulbectomy in rat. Brain Res., 974(1-2), 2003, 228-35.

[13]. R.S. Duman, G.R. Heninger, E.J. Nestler. A molecular and cellular theory of depression. Archs. Gen. Psychiat., 54(7), 1997, 597-606.

[14]. J.A. Blumenthal, M.A. Babyak, P.M. Doraiswamy, L. Watkins, B.M. Hoffman, K.A. Barbour, S. Herman, W.E. Craighead, A.L. Brosse, R. Waugh, A. Hinderliter, A. Sherwood. Exercise and pharmacotherapy in the treatment of major depressive disorder. Psychosom. Med., 69(7), 2007, 587-96.

[15]. C. Knöchel, V. Oertel-Knöchel, L. O'Dwyer, D. Prvulovic, G. Alves, B. Kollmann, H. Hampel. Cognitive and behavioural effects of physical exercise in psychiatric patients. Prog. Neurobiol., 96(1), 2011, 46-68.

[16]. M.H. Trivedi, T.L. Greer, T.S. Church, T.J. Carmody, B.D. Grannemann, D.I. Galper, A.L. Dunn, C.P. Earnest, P. Sunderajan, S.S. Henley, S.N. Blair. Exercise as an augmentation treatment for nonremitted major depressive disorder: a randomized, parallel dose comparison. J. Clin. Psychiatry., 72(5), 2011, 677-84.

[17]. M. Siwek, D. Dudek, I.A. Paul, M. Sowa-Kućma, A. Zieba, P. Popik, A. Pilc, G. Nowak. Zinc supplementation augments efficacy of imipramine in treatment resistant patients: a double blind, placebo-controlled study. J. Affect. Disord., 118(1-3), 2009, 187-95.

[18]. P. Kaliman, M. Párrizas, J.F. Lalanza, A. Camins, R.M. Escorihuela, M. Pallàs. Neurophysiological and epigenetic effects of physical exercise on the aging process. Ageing Res. Rev., 10 (4), 2011, 475-86.

[19]. E.D. Peselow, J. Corwin, R.R. Fieve, J. Rotrosen, T.B. Cooper. Disappearance of memory deficits in outpatient depressives responding to imipramine. J. Affect. Disord., 21(3), 1991, 173-83.

[20]. P. Heyn, B.C. Abreu, K.J. Ottenbacher. The effects of exercise training on elderly persons with cognitive impairment and dementia: a meta-analysis. Arch. Phys. Med. Rehabil., 85(10), 2004, 1694-704.

[21]. C. Gorenstein, S.C. de Carvalho, R. Artes, R.A. Moreno, T. Marcourakis T. Cognitive performance in depressed patients after chronic use of antidepressants. Psychopharmacol (Berl)., 185(1), 2006, 84-92.

[22]. M.A.M. Peluso, L.H. Guerra de Andrade. Physical activity and mental health: the association between exercise and mood. Clinics (Sao Paulo), 60(1), 2005, 61-70.

[23]. H. Miladi-Gorji, A. Rashidy-Pour, Y. Fathollahi, M.N. Akhavan, S. Semnanian, M. Safari. Voluntary exercise ameliorates cognitive deficits in morphine dependent rats: the role of hippocampal brain-derived neurotrophic factor. Neurobiol. Learn. Mem., 96(3), 2011, 479-91.

[24]. L. Song, W. Che, W. Min-Wei, Y. Murakami, K. Matsumoto. Impairment of the spatial learning and memory induced by learned helplessness and chronic mild stress. Pharmacol. Biochem. Behav., 83(2), 2006, 186-93.

[25]. X. Han, J. Tong, J. Zhang, A. Farahvar, E. Wang, J. Yang, U. Samadani, D.H. Smith, J.H. Huang. Imipramine treatment improves cognitive outcome associated with enhanced hippocampal neurogenesis after traumatic brain injury in mice. J. Neurotrauma., 28(6), 2011, 995-1007.

[26]. M.E. Hopkins, R. Nitecki, D.J. Bucci. Physical exercise during adolescence versus adulthood: differential effects on object recognition memory and brain-derived neurotrophic factor levels. Neuroscience, 194(1), 2011, 84-94.

[27]. H.I. Chen, L.C. Lin, L. Yu, Y.F. Liu, Y.M. Kuo, A.M. Huang, J.I. Chuang, F.S. Wu, P.C. Liao, C.J. Jen. Treadmill exercise enhances passive avoidance learning in rats: the role of down-regulated serotonin system in the limbic system. Neurobiol. Learn. Mem., 89(4), 2008, 489-96.

[28]. D. Garrigou, C.L. Broekkamp, K.G. Lloyd. Involvement of the amygdala in the effect of antidepressants on the passive avoidance deficit in bulbectomised rats. Psychopharmacol (Berl)., 74(1), 1981, 66-70. 
[29]. G. Grecksch, D. Zhou, C. Franke, U. Schroder, B. Sabel, A. Becker, G. Huether. Influence of olfactory bulbectomy and subsequent imipramine treatment on 5-hydroxytryptaminergic presynapses in the rat frontal cortex: behavioural correlates. Br. J. Pharmacol., 122(8), 1997, 1725-31.

[30]. Z. Radák, T. Kaneko, S. Tahara, H. Nakamoto, J. Pucsok, M. Sasvári, C. Nyakas, S. Goto. Regular exercise improves cognitive function and decreases oxidative damage in rat brain. Neurochem. Int., 38(1), 2001, 17-23.

[31]. N.C. Berchtold, N. Castello, C.W. Cotman. Exercise and time-dependent benefits to learning and memory. Neuroscience, 167(3), 2010, 588-97.

[32]. L. Naudon, M. Hotte, T.M. Jay. Effects of acute and chronic antidepressant treatments on memory performance: a comparison between paroxetine and imipramine. Psychopharmacol (Berl., 191(2), 2007, 353-64.

[33]. J.E. Blustein, M. McLaughlin, J.R. Hoffman. Exercise effects stress-induced analgesia and spatial learning in rats. Physiol. Behav., 89(4), 2006, 582-6.

[34]. C. Castellano. Effects of chlorpromazine and imipramine on discrimination learning, consolidation, and learned behavior in two inbred strains of mice. Psychopharmacol (Berl)., 53(1), 1977, $27-31$.

[35]. M.W. Marlatt, M.C. Potter, P.J. Lucassen, H. van Praag. Running throughout middle-age improves memory function, hippocampal neurogenesis and BDNF levels in female C57B1/6J mice. Dev. Neurobiol., 72(6), 2012, 943-52..

[36]. X. Liu, Le.J. Yang, S.J. Fan, H. Jiang, F. Pan. Swimming exercise effects on the expression of HSP70 and iNOS in hippocampus and prefrontal cortex in combined stress. Neurosci. Lett., 476(2), 2010, 99-103.

[37]. R.G. Lister. Ethologically-based animal models of anxiety disorders. Pharmacol. Ther., 46(3), 1990, 321-40.

[38]. S. Pellow, S.E. File. Anxiolytic and anxiogenic drug effects on exploratory activity in an elevated plus-maze: a novel test of anxiety in the rat. Pharmacol. Biochem. Behav., 24(3), 1986, 525-9.

[39]. A.P. Cruz, F. Frei, F.G. Graeff. Ethopharmacological analysis of rat behavior on the elevated plus-maze. Pharmacol. Biochem. Behav., 49(1),1994, 171-6.

[40]. J.C. Cole, R.J. Rodgers. Ethological comparison of the effects of diazepam and acute/chronic imipramine on the behaviour of mice in the elevated plus-maze. Pharmacol. Biochem. Behav., 52(3), 1995, 473-8.

[41]. J.N. Crawley. Exploratory behavior models of anxiety in mice. Neurosci. Biobehav. Rev., 9(1), 1985, 37-44.

[42]. A. Ennaceur. One-trial object recognition in rats and mice: methodological and theoretical issues. Behav. Brain. Res., 215(2), 2010, 244-54.

[43]. R.N. Walsh, R.A. Cummins. The Open-Field Test: a critical review. Psychol. Bull., 83(3), 1976, 482-504.

[44]. A.V. Kalueff, M. Wheaton, D.L. Murphy. What's wrong with my mouse model? Advances and strategies in animal modeling of anxiety and depression. Behav. Brain Res., 179(1), 2007, 1-18.

[45]. E. Binder, S.K. Droste, F. Ohl, J.M. Reul. Regular voluntary exercise reduces anxiety-related behaviour and impulsiveness in mice. Behav. Brain Res., 155(2), 2004, 197-206.

[46]. L. Mazzardo-Martins, D.F. Martins, R. Marcon, U.D. dos Santos, B. Speckhann, V.M. Gadotti, A.R. Sigwalt, L.G. Guglielmo, A.R. Santos. High-intensity extended swimming exercise reduces pain-related behavior in mice: involvement of endogenous opioids and the serotonergic system. J. Pain, 11(12), 2010, 1384-93.

[47]. F. Zhang, Y. Wu, J. Jia. Exercise preconditioning and brain ischemic tolerance. Neuroscience, 177(1), 2011, 1706.

[48]. F. Chavant, J. Deguil, S. Pain, I. Ingrand, S. Milin, B. Fauconneau, M.C. Pérault-Pochat, C. Lafay-Chebassier. Imipramine, in part through tumor necrosis factor alpha inhibition, prevents cognitive decline and beta-amyloid accumulation in a mouse model of Alzheimer's disease. J. Pharmacol. Exp. Ther., 332(2), 2010, 505-14.

[49]. D.G. Mumby, M.J. Glenn, C. Nesbitt, D.A. Kyriazis. Dissociation in retrograde memory for object discriminations and object recognition in rats with perirhinal cortex damage. Behav. Brain Res., 132(2), 2002, 215-26. 